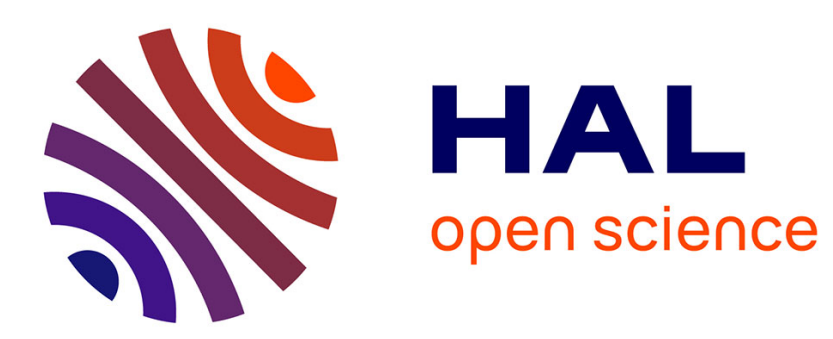

\title{
Optimization of maintenance strategy of renewable energy production system (REPS) for minimizing production loss
}

Nicolas Tchertchian, Dominique Millet

\section{- To cite this version:}

Nicolas Tchertchian, Dominique Millet. Optimization of maintenance strategy of renewable energy production system (REPS) for minimizing production loss. International Journal on Interactive Design and Manufacturing, 2016, 10 (3), pp.229-234. 10.1007/s12008-016-0331-6 . hal-01401951

\section{HAL Id: hal-01401951 \\ https://hal.science/hal-01401951}

Submitted on 24 Nov 2016

HAL is a multi-disciplinary open access archive for the deposit and dissemination of scientific research documents, whether they are published or not. The documents may come from teaching and research institutions in France or abroad, or from public or private research centers.
L'archive ouverte pluridisciplinaire HAL, est destinée au dépôt et à la diffusion de documents scientifiques de niveau recherche, publiés ou non, émanant des établissements d'enseignement et de recherche français ou étrangers, des laboratoires publics ou privés. 


\title{
Optimization of maintenance strategy of Renewable Energy Production System (REPS) for minimizing production loss
}

\author{
Tchertchian. Nicolas ${ }^{\top}(\bowtie)$, Millet. Dominique ${ }^{\top}$ \\ ${ }^{1}$ Avenue de l'université, COSMER, University of Toulon, 83000 Toulon, France \\ Received: day month year / Revised: day month year / Accepted: day month year (automatically inserted by the publisher)
}

\begin{abstract}
The concept of Eco-Maintenance aims to prolong the lifetime of the system to maintain while minimizing environmental losses due to maintenance. This concept is developed for Renewable Energy Production System (Reps) like Wind Turbines or Photovoltaic Panel. REPS generate clean and inexhaustible energy. However the production of this energy is unpredictable because it depends on the weather. Moreover failures that occur on the means of production make the operation less interesting. However the implementation of technical resources (fault detection sensor, vehicles and transfer system for technicians, tools and spare parts) improves the performance of the production system. In this paper a model for REPS with an application on Wind Energy Production system (Offshore Wind Farm + Maintenance Systems) was developed and simulations have been performed. Hence we show the importance to design and optimize the maintenance the REPS for reducing cost and environmental issues.
\end{abstract}

\section{KEYWORDS}

Eco-Maintenance - Ecodesign - Renewable Energy - Offshore windfarm

\section{Introduction}

The Renewable Energies Production System (REPS) do not generate direct emissions and do not produce hazardous waste. Nor do they deplete natural resources. However the production of this energy generates indirect pollution due to the high failure rate of the industrial production system, the maintenance and the unavailability of energy source [1]. The life cycle of the REPS is defined Figure 1.During the use phase the power system (wind turbine, Marine current power, photovoltaic panels...) can fail and need Operations and Maintenance (O\&M).During O\&M, technicians are transported to the production site. The impacts generated by this mean of transport should be accounted in environmental assessment.During the period of 
unavailability of the renewable energy source, the energy that is not produced must be elsewhere. This creates economic costs and generates additional environmental impacts associated with the production of non-renewable energy (nuclear power plant, thermal power plant...). One way to reduce these indirect impacts is to optimize the REPS lifetime while minimizing environmental losses due to maintenance by mobilizing the concept of Eco-Maintenance.The structure of this paper is as follows. In Section 2, we provide a brief overview on optimization of operational resources for the maintenance of REPS. Section 3 deals with the Complex system modeling for environmental optimization of REPS then for Wind Energy Production system. Section 4 presents some O\&M scenarios and their environmental impact through Life Cycle Assessment method.Subsequently, the relevant parameters influencing the overall performance of REPS are identified then and operational issues are discussed in Section 5.

\section{Optimization of operational resources for the maintenance of REPS}

The maintenance optimization is the process that seeks to balance the constraints of maintenance (legislative, economic, technical, and environmental) and the resources used to run the maintenance program (human resources, spare parts, equipment, arrangements, etc.) [2]. The main objective of the maintenance optimization is to determine the strategy which provide the best balance between direct cost service (labor, materials, administration ...) and the impact on the system if maintenance is not performed as expected (loss of production and profits) while avoiding the consequences on health, safety and environment by mobilizing the concept of "Green" Maintenance [3].

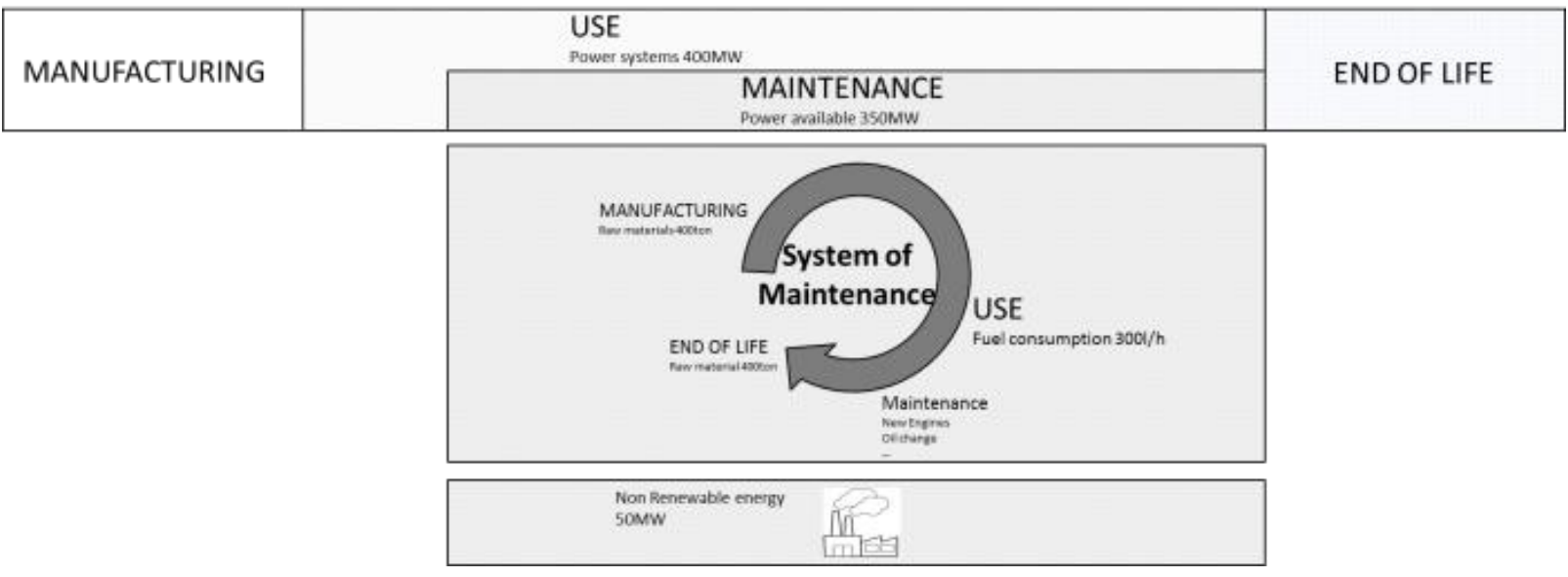

Figure 1:Life cycle of REPS

To optimize the maintenance of REPS two types of action are possible; first by acting on internal factors (organizational improvement of the maintenance process: fault detection as early as possible [4], automatic detection of deviations performance of WTs [5], planning maintenance [6] ...); then acting on the external factors in improving the performance of system of maintenance (optimization of logistics scenarios [7], fleet composition, type of truck, vessel, helicopter ... [8]).

In practice, two strategies are confronting:

- Identify the risks of failure to intervene earlier 
- Repair as soon as possible in difficult weather conditions to avoid extended downtime of Power system.

In this paper we deal with the second option.

The achievement of maintenance activities such as inspection, preventive maintenance, and replacement of wear components increases the direct costs of maintenance. In return, the risk of incidents or consequences of failure to complete the required maintenance decreased [9].

\section{Complex system modeling for environmental optimization of REPS}

\subsection{Scope of Reps}

REPS are complex system composed by 3 linked subsystems.

1. The industrial system responsible for converting renewable energy into electricity source.

2. Location of these systems.

3. External resources maintaining the industrial system.

Modeling parameters for industrial system (solar panels, wind turbines, submarine turbines...) are the power, the lifetime and the reliability of its components.

Location of REPS is characterized byweather conditions (sun, wind, swell...), distance and mean of transport to reach production site (trucks, helicopter, ship, submarine...).

For the maintenance of the industrial system (repair breakdowns or preventive maintenance), external resources are mobilized to transport the technicians on the production site, store and carry tools and spare parts. The performance of these resources will influence the environmental impact of REPS

The performance of Maintenance Systems (SM) is characterized by the time to access to the site, the range of use according weather conditions and its life cycle (Raw materials/ Manufacturing, fuel consumption, maintenance: replacement of wear parts, and end of life).

\subsection{Offshore Wind Energy Production System}

The remainder of this paper reports findings from environmental assessment and influences of external factors for wind energy production system (Figure 2) [10].

The turbine is the power system of REPS. In a simplified way, the wind turbine blades transform the kinetic energy of wind into mechanical energy and then into electricity by a generator. The characteristic of a wind power curve gives the electric power according to wind speed for a wind turbine.

The number of turbines in wind farm and their power are used to quantify the energy generated by the wind farm according wind conditions on the production site. The lifespan of the components is used to design corrective maintenance (by randomly generating failures based on the failure rate of various components defined by a group of experts [11] and planned preventive maintenance.

The location of offshore wind farms in high sea makes them more difficult to perform O\&Ms. Technicians must be transported with ships on production site, eventually by helicopter. Then the transfer on wind turbines requires optimal weather conditions to ensure their safety.

Distance from shore results in two types of maintenance strategies [4]; the first based on maintenance made from shore: technicians return to port after each intervention; the second strategy for wind farm away from the coast, technicians are permanently close to the farm.

Weather conditions (average wind speed and significant wave height) are defined for a given wind farm location. These data are needed to evaluate the energy production of the wind farm and to plan the schedule of preventive maintenance. More the wind is powerful and 
constant more the load factor is better but in return the transfer of technicians is difficult (depending of the system of maintenance used).

Our work is focused on the search for an optimized maintenance system.To develop logistics scenarios, the model integrates different parameters:

- The ability to transfer technicians (number of technicians)

- The speed of response depending on the distance to the site and performance in weather conditions (wind and significant wave height limits).

The different types of SM for offshore wind farms are:Crew Transfer Vessels (CTV), helicopters and
Fast Support Vessel (FSV). CTV is used to transport between 12 and 16 technicians on production site located until 30 nautical miles (nm) form shore at 20 knots maximal speed. But they are limited by weather condition. The significant wave height limitations of CTV are usually assumed with $1.5 \mathrm{~m}$. When sea conditions are harsh, operators could charter helicopters. When the distance from shore is more than $30 \mathrm{~nm}$, others solutions exists. Operators need a third type of SM. These vessels (also called "floatel") are bigger and stay near the wind farm on a $24 \mathrm{~h} / 7$ days basis for several weeks. For example Fast Support Vessel (FSV) is able to accommodate up to 48 technicians. These boats are capable of transferring technicians with the worst sea conditions between $1.5 \mathrm{~m}$ and $3 \mathrm{~m}$.

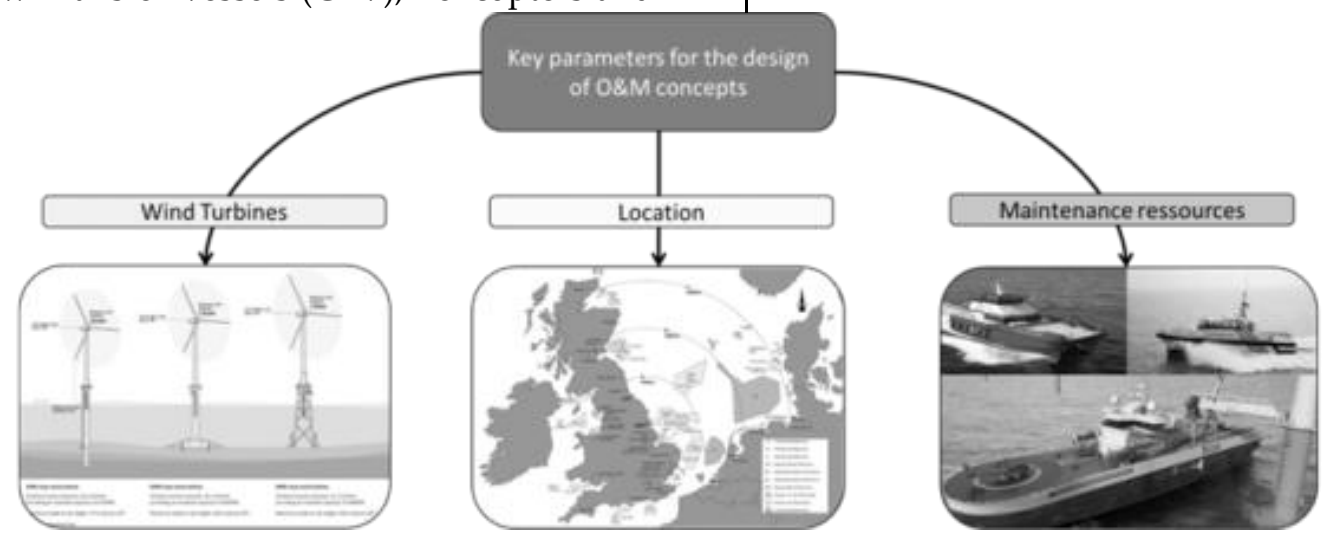

Figure 2: Subsystems for Wind Energy production system

During the winter season, sometimes access to turbines is inaccessible for long periods, resulting in a long periods of downtime and production losses [12]. Thus, these constraints are arguments in favor of investment in more robust vessels able to safely transfer the technicians to the turbines in harsh weather conditions $(>1.5 \mathrm{~m})$. But the sophistication of maintenance systems not she leads to an increase of impacts and costs over the full life cycle of the system?

Figure 3shows the distribution of impacts generated by the wind power production under different scenarios.Wind energy production system, in perfect case (i.e. without maintenance), produces clean energy with a yield of $40 \%$. The rest of the energy is to be produced in a conventional manner (non-renewable) and the impact is due to manufacturing of the turbine. 


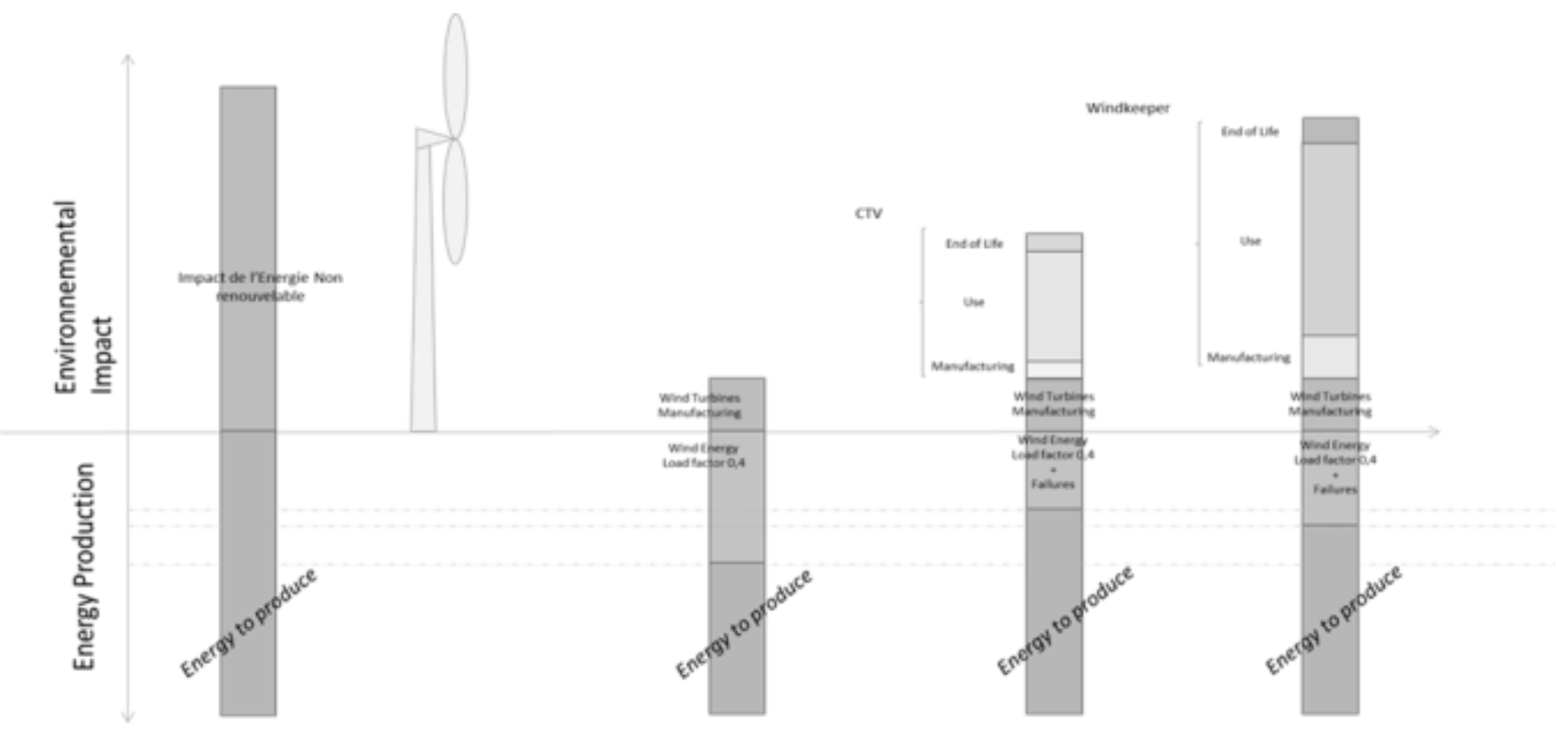

Figure 3: Distribution des Impacts dans la production d'énergie éolienne

In reality wind turbine fail and their efficiency fall under $40 \%$. Consequently more non-renewable energy must be produced and in addition to the manufacturing impact of wind turbine, the impact of the life cycle of SM has to be accounted. The goal is to obtain the best efficiency of the wind energy production system with the least impact.

\section{Case Study: Assessment of Wind farms maintenance}

Unplanned maintenances are modeled using Annual Failure Rate (AFR). The model is built around an event generator. The principle of this generator is to randomly assign failures on all WTs over their lifetime and deduct the planned maintenance affecting the wind farm. The generator is built around a global optimization method of the maintenance system, detailed on [13].

We assumed that repair time is 6 hours per turbine and planned maintenance time is 4 hours per turbine.Preventive maintenance is stopped when a turbine fails. Maintenance operations resume when the turbine is repaired.

The functional unit of the Wind Energy Production System is defined by a 20 years lifetime, a wind farm composed by eighty $6 \mathrm{MW}$ turbines.

- Environmental assessment of O\&M scenarios for wind farms at 50 nautical miles from shore

Three different systems are evaluated, a CTV and 2 bigger vessels ("floatel"): a 90 meters long FSV able to accommodate up to 48 technicians and an alternative system capable of transferring up to 24 technicians through a Small Waterplane Area Twin Hull (SWATH) boat coupled to a dynamic stabilization system on a 24 hour/7 day basis and up to $3 \mathrm{~m}$ of significant wave height.

To comply with the functional unit, four vessels need to be deployed against one SWATH and one FSV. Figure 4 shows the impact of the life cycle of three SM on raw materials manufacturing use and end of life phases the impact due to the non-renewable energy to produce when wind turbines are stopped. 


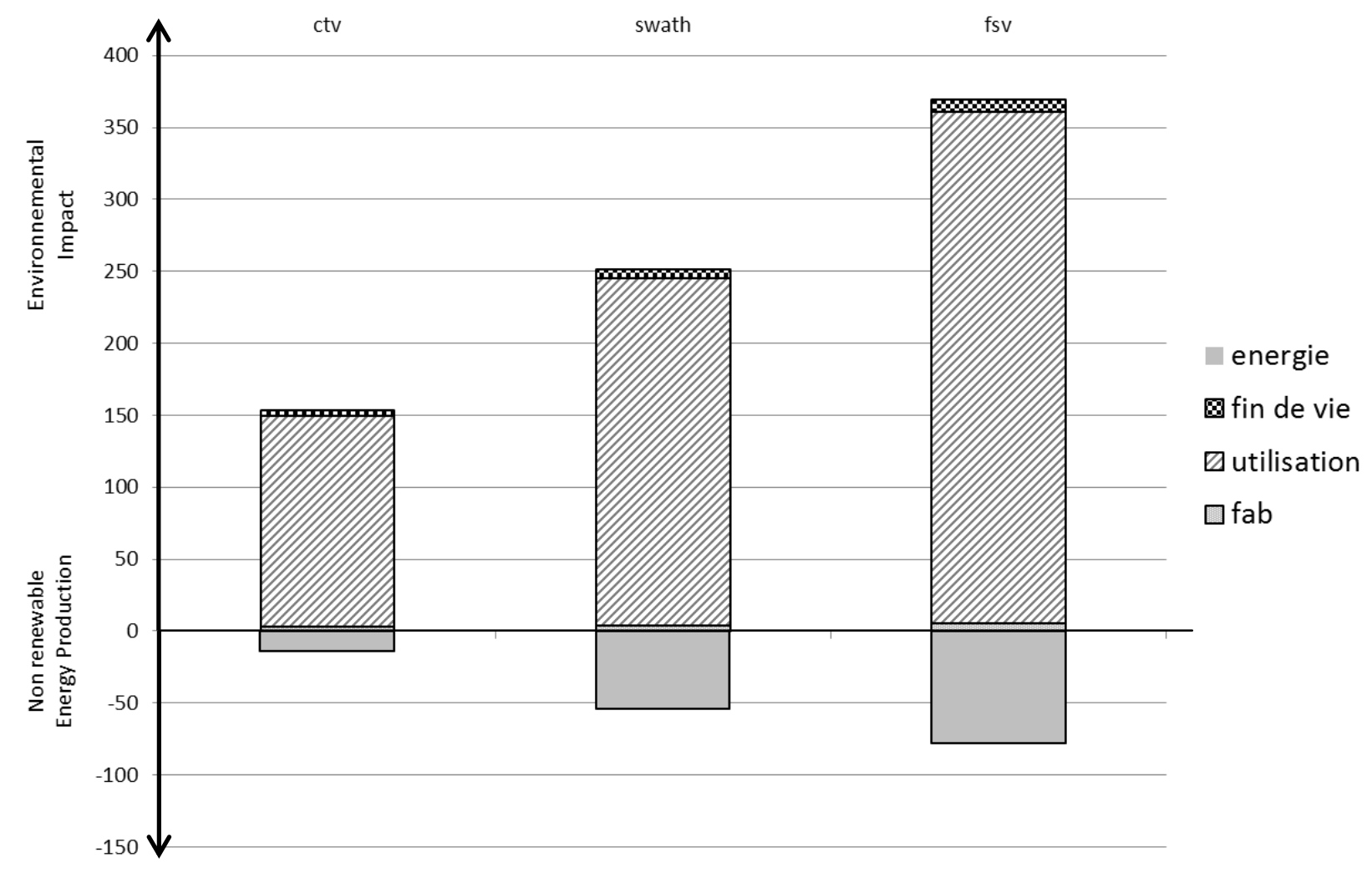

Figure 4:Environmental assessment of O\&M strategy for windfarm at $100 \mathrm{~km}$ from shore

The round-trips of $4 \mathrm{CTV}$ between the $50 \mathrm{~nm}$ separating the shore from production site help make CTV environmentally less efficient than the two "floatel" alternatives. The SWATH vessel is the least impacting solution on the use phase. Moreover both "floatel" systems allow a gain of consumption of renewable energy production equivalent to two days of production per turbine per year.

- Influence of distance from shore to production site on Environmental assessment of O\&M scenarios

More the wind farm is far away from shore more CTV trips are long. The result is an effective duration of working time by technicians shorter. To perform all the tasks planned it is necessary to have several CTV. On Figure 5, maintenance performed by CTV is optimal solution when production site is located at less than $10 \mathrm{~km}$ from shore. 


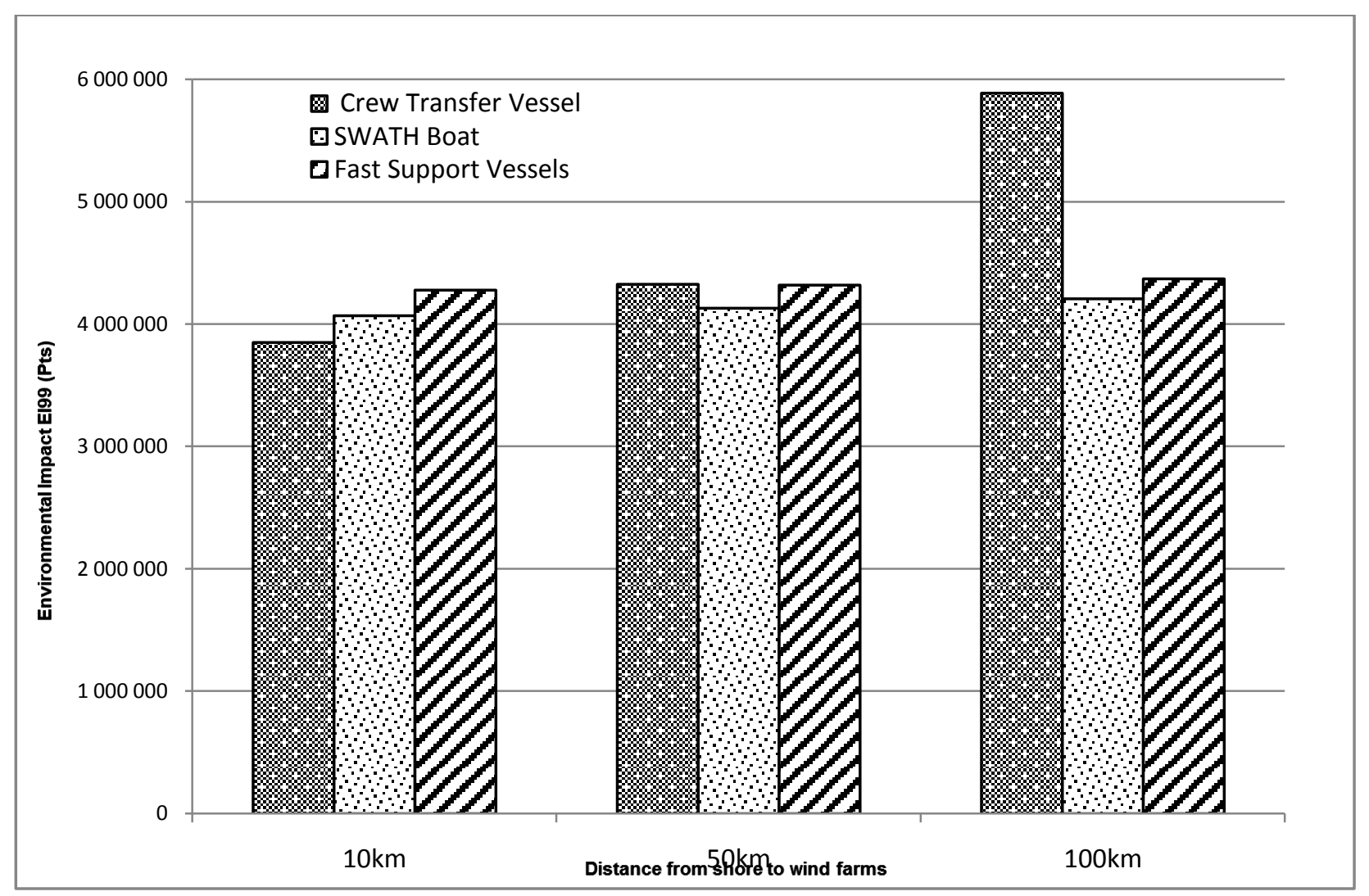

Figure 5: Influence of distance from shore on environmental assessment of O\&M strategy

However at $50 \mathrm{~km}$ from shore the situation becomes less obvious, SWATH vesselis the best solution but the difference is not substantial. At $100 \mathrm{~km}$ from shore the optimal solution is obviously SWATH vessels. Indeed, the environmental gain is about 30\% less impactful than CTV for reason mentioned above.

\section{Conclusion}

This approach should be applied at the same time as designing WT. It would be interesting to assess the size of the wind farm coupled with the power of WT. For example, is it better to design a $500 \mathrm{MW}$ wind farm composed by $80 * 6 \mathrm{MW}$, or composed by $62 * 8$ MW WTs.

The failure rate of these turbines is assumed to be different (because the technologies used are different).

Unavailability of 8 MW WTs may be more important generating more environmental impact with production of non-renewable energy. In exchange, the maintenance of a smaller wind farm may induce fewer resources in terms of maintenance. In conclusion, the environmental performance of Systems of Energy Production and system of maintenance are interdependent.

\section{References}

[1] Christensen, P.; Giebel, G. (2001). Availability of wind turbines in remote places.A statistical and a real-time view.In P. Helm, \& A. Zervos (Eds.), Wind energy for the new millennium.Proceedings. (pp. 162-165). München: WIP Renewable Energies.

[2] System Reliability Center (SRC). Maintenance Optimization [Online].

http://src.alionscience.com/pdf/MaintOptimDesc.pdf (accessed Feb 26, 2017).

[3] Ajukumar, V. N.; Gandhi, O. P. (2013) Evaluation of green maintenance initiatives in design and development of mechanical systems using an integrated approach, Journal of Cleaner Production, Volume 51, 15 pp. 34-46

[4] Tavner, P.; Spinato, F.; Van BusselGJW.;Koutoulakos, E., 2008. Reliability of different wind turbine concepts with relevance to offshore application.European Wind Energy 
Conference (EWEC2008), Brussels, Belgium.

[5] Sainz, E.; Llombart, A.; Guerrero, J. J. (2009) Robust filtering for the characterization of wind turbines: Improving its operation and maintenance, Energy Conversion and Management, Volume 50, Issue 9, September, Pages 2136-2147

[6] Nielsen, J. J.;Sфrensen, J. D. (2010) Planning of O\&M for Offfshore Wind Turbines using Bayesian Graphical Models. Reliability, Risk and Safety : back to the future: ESREL 2010 : annual conference, 5-9 September 2010, Rhodes, Greece.

[7] Scheu, M.;Matha, D.; Hofmann, M.;Muskulus, M. (2012) Maintenance Strategies for Large Offshore Wind Farms. Energy Procedia (24) pp. $281-288$

[8] Halvorsen-Weare, E. E.; Gundegjerde, C.; Halvorsen, I. B.; Hvattum, L. M.; Nonås, L. M. Vessel fleet analysis for maintenance operations at offshore wind farms. Energy Procedia, 35:167-176, 2013

[9] British Standard Institution, BS3811 Glossary of maintenance terms interotechnology, BSI, London, 1984

[10] Münsterberg, T.; Rauer, R.; Jahn, C. 2013. Design and Evaluation Tool for Operations and Maintenance Logistics Concepts for Offshore Wind Power Plants. Journal of Energy and Power Engineering 7 (2013) p. 2054-2059.
[11] Ribrant, J., Bertling, L.M. (2007) Survey of Failures in Wind Power Systems With Focus on Swedish Wind Power Plants During 1997-2005. Energy Conversion, IEEE Transactions on , vol.22, no.1, pp.167,173.

[12] Obdam, T.;Braam, H.; van de Pieterman, R., Rademakers, L. (2011) O\&M Cost Estimation \& Feedback of Operational Data. Wind Farm - Technical Regulations, Potential Estimation and Siting Assessment. Chapter 2.

[13]Tchertchian, N.; Millet, D. Eco-Maintenance for Complex Systems: Application on System of Renewable energy production. 3rd International Symposium on Environment Friendly Energies and Applications (EFEA 2014), Paris, France, 2014. 